\title{
Estudo da utilização do efluente de biodigestor no cultivo hidropônico do meloeiro' ${ }^{1}$
}

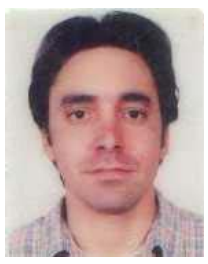

Luiz V. E. Villela Junior², Jairo A. C. de Araújo ${ }^{3}$ \& Thiago L. Factor ${ }^{4}$

\begin{abstract}
1 Parte da Dissertação de Mestrado apresentada pelo primeiro autor à FCAV/UNESP - Campus de Jaboticabal
2 Doutorando. Depto. Engenharia Rural da FCAV/UNESP. Via de Acesso Prof. Paulo Donato Castellane, s/n., CEP 14884-900, Jaboticabal, SP. Fone: (16) 3209-2637. E-mail: villelajr@zipmail.com.br

3 Depto. Engenharia Rural da FCAV - UNESP. Fone: (16) 3209 2637. E-mail: jaca@fcav.unesp.br (Foto)

${ }^{4}$ Mestrando, FCAV/UNESP. Fone: (16) 3209 2637. E-mail: factor@fcav.unesp.br
\end{abstract}

Protocolo $11-4 / 2 / 2002$ - Aprovado em 14/4/2003

\begin{abstract}
Resumo: Objetivando-se o aproveitamento do efluente de biodigestor no cultivo hidropônico do meloeiro, desenvolveu-se a presente pesquisa. O experimento foi conduzido no Departamento de Engenharia Rural da Faculdade de Ciências Agrárias e Veterinárias da UNESP, campus de Jaboticabal, cultivando-se o meloeiro (Cucumis melo L. cv. Bonus $\mathrm{n}^{\circ} 2$ ). O delineamento experimental utilizado foi em blocos casualisados, com 6 repetições, cujos tratamentos foram: 1) cultivo hidropônico em sistema fechado tipo NFT ("nutrient film technique") com uso de solução nutritiva organo-mineral (biofertilizante com complementação mineral); 2) cultivo hidropônico em sistema fechado tipo NFT, com uso de solução nutritiva $100 \%$ mineral; 3) cultivo hidropônico em sistema aberto, com substrato e solução nutritiva organo-mineral e 4) cultivo hidropônico em sistema aberto, com substrato e solução nutritiva $100 \%$ mineral. O biofertilizante e o substrato foram obtidos a partir do efluente de biodigestor, produzido com estrume bovino. As plantas cultivadas no tratamento 1 tiveram desenvolvimento prejudicado, devido ao acúmulo de partículas sólidas junto ao sistema radicular. $\mathrm{O}$ tratamento 2 proporcionou às plantas desenvolvimento vegetativo mais rápido e maior produtividade. Os frutos produzidos no tratamento 2 apresentaram maior peso, formato mais alongado e maior teor de sólidos solúveis totais. A substituição parcial de adubos minerais por biofertilizante mostrou-se possível em sistema hidropônico aberto com substrato.
\end{abstract}

Palavras-chave: hidroponia, Cucumis melo L, biofertilizante, substrato

\section{Utilization of biodigester effluent in the hydroponic cultivation of melon}

\begin{abstract}
With the objective to use effluent of biodigestor in the hydroponic cultivation, an experiment was conducted in the Department of Rural Engineering Faculty of Agricultural and Veterenary Sciences of UNESP, campus of Jaboticabal where a melon crop (Cucumis melo L. cv. Bonus $\mathrm{n}^{\circ}$ 2) was cultivated. The experimental design used was a randomized blocks, with 6 repetitions and the treatments studied were: 1 ) hydroponic cultivation in closed system type NFT (nutrient film technique) with use of organic-mineral nutrient solution (biofertilizer with mineral complementation); 2) hydroponic cultivation in closed system type NFT with use of $100 \%$ mineral solution; 3 ) hydroponic cultivation in open system, with substrate and organicmineral nutrient solution and 4) hydroponic cultivation in an open system, with substrate and $100 \%$ mineral solution. The biofertilizer and the substrate were obtained from biodigestor effluent produced with cowdung. Plant development in treatment 1 was affected due to accumulation of solid particles in the root system. Treatment 2 provided to the plants rapid vegetative development and higher productivity. The fruits produced in treatment 2 presented higher weight, more elongated shape and higher total soluble solid content. A partial substitution of mineral fertilizers by biofertilizers showed viability of hydroponic cultivation of the melon plant in an open system with substrate.
\end{abstract}

Key words: hydroponics, Cucumis melo L, biofertilizer, substrate 


\section{INTRODUÇÃO}

Nas últimas décadas, o setor agrícola sofreu acentuada modernização. A evolução que originou a moderna agricultura, foi fundamentada na necessidade de se produzir mais. Para se atingir este objetivo, foi necessário melhorar-se as condições para o desenvolvimento das plantas por meio da adubação química, do uso de defensivos agrícolas, da melhoria genética das plantas, da irrigação, do manejo de solo e de tantos outros insumos e técnicas capazes de conduzir os cultivos a melhores produtividades.

Com esta evolução das técnicas de cultivo de plantas, desenvolveu-se a plasticultura e a hidroponia. O termo hidroponia ("hidro" = água e "ponos" = trabalho) foi criado em 1930 pelo Dr. W.F. Gerike, da Universidade da Califórnia, que popularizou o cultivo das plantas em ausência de solo (Jones Jr., 1982). Segundo Furlani (1999), o cultivo hidropônico no Brasil foi introduzido em 1987, por produtores paulistas, que trouxeram a técnica do Japão. Com o passar do tempo, desenvolveram-se algumas variantes do cultivo hidropônico, entre as quais se destacam duas como mais utilizadas: a hidroponia tipo NFT ("nutrient film technique") e o cultivo em substratos.

Conforme Furlani et al. (1999) para o cultivo hidropônico utilizam-se recipientes com material (substrato) que sirva de sustentação para as plantas, onde a solução nutritiva é aplicada e drenada pela parte inferior.

A técnica do filme de nutrientes, designada NFT e desenvolvida por Alen Cooper na década de 60 no Glasshouse Crops Research Institute (Inglaterra), é pesquisada e citada por muitos autores, entre eles Jones Jr. (1982), Jensen \& Collins (1985), Ueda (1990), Lejeune \& Balestrazzi (1992), Castellane \& Araújo (1994) e Furlani (1995). De acordo com Fossati (1986), no sistema NFT a planta se desenvolve com $2 / 3$ de seu sistema radicular submerso na solução nutritiva, fornecida à planta sob a forma de um fluxo intermitente, de onde ela retira os nutrientes, enquanto a porção restante do sistema radicular se desenvolve ao ar livre para a absorção de oxigênio. A solução nutritiva é fornecida às plantas por canais de cultivo, que também têm a função de sustentar o sistema radicular das plantas e oferecer barreiras para que a luz não atinja a solução, evitando a evaporação da solução nutritiva e o crescimento de algas. A solução nutritiva é liberada nos canais, passando por gravidade pelas raízes das plantas e chegando a um reservatório, de onde é novamente bombeada até os canais.

Os sistemas hidropônicos também podem ser classificados em sistemas abertos e fechados; no primeiro caso, a solução nutritiva é aplicada uma única vez às plantas, não sendo reutilizada, sendo normalmente aplicado em cultivo com substratos; já no sistema fechado, o excesso de solução nutritiva é recuperado e recirculado, sendo normalmente utilizado no sistema hidropônico tipo NFT (Castellane \& Araújo, 1994).

$\mathrm{O}$ uso indiscriminado de fertilizantes minerais, tanto em sistemas convencionais de cultivo quanto em sistemas hidropônicos, pode causar sérios danos ao meio ambiente e provocar escassez precoce de muitas reservas naturais de alguns elementos essenciais à agricultura, fato este que deu origem a muitos estudos e aplicações práticas, com o intuito de diminuir ou até mesmo substituir, os fertilizantes minerais por biofertilizantes ou fertilizantes orgânicos.

Sabe-se que, hoje, qualquer material orgânico submetido a um processo de biodigestão anaeróbia (através de um biodigestor) produz biogás e efluentes. Segundo Bryant (1979) e Bungay (1981) apud Fries \& Aita (1990), esses efluentes apresentam características distintas em relação ao material original (antes da biodegradação). Arias (1977) afirmou que tais efluentes podem servir de fertilizantes agrícolas, alimento para animais e acondicionantes para o solo. Arias (1981) evidencia que os efluentes de biodigestores apresentam nutrientes mais facilmente absorvíveis pelas plantas, quando comparados ao material orgânico antes do processo de biodigestão. Por outro lado, com o objetivo de diferençar os efeitos da adição de dosagens de esterco bovino "in natura" e efluente de biodigestor sobre o cultivo do sorgo em solo, Fries \& Aita (1990) concluíram que a quantidade de nitrogênio absorvido e o rendimento de matéria seca foram maiores nos tratamentos com o efluente de biodigestor, enquanto Mastrocola (1983) e Valeriano (1987) verificaram que os efeitos da utilização de biofertilizantes provenientes de biodigestores são benéficos na produção de milho, em sistema de cultivo convencional em solo.

Vazquez et al. (1995) avaliaram a utilização de esterco bovino fermentado em condições anaeróbias como biofertilizante na cultura da cebola, aumentando significativamente o rendimento de bulbos, mas nos tratamentos com aplicação do resíduo via foliar, eles conseguiram a diminuição do ataque de pragas e doenças.

Como demonstrado, pesquisas com a utilização de efluentes orgânicos, como aqueles provenientes de biodigestores, têm sido desenvolvidas na área de cultivo em solo; contudo, poucas pesquisas relacionam a utilização de efluentes de biodigestores em cultivos hidropônicos de plantas. Dentro deste enfoque, realizou-se a presente pesquisa, com o objetivo de se estudar o comportamento do meloeiro, cultivado em sistemas hidropônicos fechado, tipo NFT, e aberto, com substrato, utilizando-se de efluente de biodigestor como substrato e solução nutritiva.

\section{MATERIAL E MÉTODOS}

O presente estudo foi desenvolvido em ambiente protegido localizado no Setor de Plasticultura do Departamento de Engenharia Rural da Faculdade de Ciências Agrárias e Veterinárias - UNESP, campus de Jaboticabal, localizados a uma Latitude de $21^{\circ} 17^{\prime} 5^{\prime \prime}$ S e Longitude de $48^{\circ} 17^{\prime}$ 9" W. O clima da região, segundo classificação de Köppen, é do tipo Cwa, subtropical, relativamente seco no inverno e com chuvas no verão, apresentando temperatura média anual de $22{ }^{\circ} \mathrm{C}$ e precipitação média anual de $1552 \mathrm{~mm}$ (Volpe et al., 1989).

$\mathrm{O}$ ambiente protegido utilizado, comumente denominado casa-de-vegetação, foi do tipo capela, com $3 \mathrm{~m}$ de pé direito, $51 \mathrm{~m}$ de comprimento, $10 \mathrm{~m}$ de largura, coberta com filme de polietileno de baixa densidade, com $150 \mu$ de espessura e com aditivo ultravioleta. A lateral da casa de vegetação foi protegida com telas de polipropileno, com $30 \%$ de sombreamento e $1 \mathrm{~m}$ de largura. 
A cultura utilizada no experimento foi o meloeiro (Cucumis melo L.) híbrido Bônus $\mathrm{n}^{\circ}$ 2, semeado em 26/7/2000 e transplantado em 4/9/2000, aos 40 dias após a semeadura (DAS).

Foram estudados 4 tratamentos: 1) cultivo hidropônico em sistema fechado tipo NFT (Nutrient Film Technique), com uso de solução nutritiva organo-mineral (biofertilizante com complementação mineral); 2) cultivo hidropônico em sistema fechado tipo NFT, com uso de solução nutritiva 100\% mineral; 3) cultivo hidropônico em sistema aberto, com substrato e solução nutritiva organo-mineral (biofertilizante com complementação mineral) e 4) cultivo hidropônico em sistema aberto, com substrato e solução nutritiva $100 \%$ mineral.

Para o sistema fechado tipo NFT utilizado nos tratamentos 1 e 2, empregaram-se tubos de PVC com 150 mm de diâmetro e $6 \mathrm{~m}$ de comprimento, perfurados em sua parte superior com orifícios de $100 \mathrm{~mm}$ de diâmetro, onde as plantas foram fixadas e cultivadas. Estes, por sua vez, foram colocados a nível do solo dentro da casa-de-vegetação e fixados com suportes, até que atingissem declividade de 2 a 2,5\%, para que a solução nutritiva pudesse ser escoada por gravidade. Os tubos (canais de cultivo) foram espaçados em $1 \mathrm{~m}$ e perfurados em sua parte superior, de 0,5 em 0,5 m, adotando-se o espaçamento de $1 \mathrm{x}$ 0,5 m; assim, cada tubo suportou 12 plantas, deixando-se $0,25 \mathrm{~m}$ em cada ponta de tubo. Os sistemas hidráulico de alimentação e retorno, foram devidamente dimensionados e instalados para que as plantas pudessem estar adequadamente supridas das necessidades diárias de água e nutrientes. Para o bombeamento da solução nutritiva de forma intermitente até os canais de cultivo, utilizaram-se conjuntos motobombas da marca KSB modelo P-500 com 0,5 CV de potência, que foram acionadas em intervalos de 15 min através de "timers".

Para o sistema de cultivo aberto (com substrato) utilizado nos tratamentos 3 e 4, seguiu-se o mesmo esquema adotado para o sistema hidropônico tipo NFT, com algumas diferenciações. O substrato utilizado para este cultivo foi colocado dentro dos tubos de $150 \mathrm{~mm}$, para servir de sustentação às raízes e de material de retenção da solução nutritiva. Os canais de cultivo além dos orifícios na parte superior, receberam pequenos furos na parte inferior, de $1 \mathrm{em} 1 \mathrm{~m}$, para que o excesso de solução pudesse escoar. A irrigação nesses tratamentos foi realizada com uso de gotejadores individuais da marca Carborundum, modelo GFT, com vazão de $2,5 \mathrm{~L} \mathrm{~h}^{-1}$ à pressão de trabalho de $0,7 \mathrm{~atm}$, que aplicavam a solução nutritiva no substrato, pelos orifícios onde foram fixadas as plantas.

Para a obtenção do biofertilizante e do substrato, o efluente de biodigestor, resultado da fermentação anaeróbia de estrume bovino, foi coletado e separado em partes sólida (substrato) e líquida (biofertilizante) por processo de decantação; em seguida, a parte líquida foi armazenada em um tanque de reserva para posterior utilização como biofertilizante, enquanto a parte sólida foi seca ao sol, para posterior elaboração do substrato.

A solução nutritiva $100 \%$ mineral utilizada nos tratamentos 2 e 4, foi a recomendada por Castellane \& Araújo (1994) para a cultura do meloeiro, com $168 ; 39 ; 222 ; 153 ; 24,6 ; 36 ; 2 ; 0,66$; 0,21; 0,25; 0,02 e 0,05 mg de N, P, K, Ca, Mg, S, Fe, Mn, B, Zn, $\mathrm{Cu}$ e Mo, respectivamente. Para se atingir essas concentrações de nutrientes, utilizaram-se somente fontes minerais de nutrientes, descritas nas Tabelas 1 e 2 .

Tabela 1. Concentração de cada componente da solução nutritiva $100 \%$ mineral utilizada nos tratamentos 2 e $4^{*}$

\begin{tabular}{lc}
\hline \multicolumn{1}{c}{ Componente } & Concentração $\left(\mathrm{mg} \mathrm{L}^{-1}\right)$ \\
\hline Nitrato de cálcio & 805,30 \\
MAP & 186,25 \\
Nitrato de potássio & 167,15 \\
Cloreto de potássio & 294,30 \\
Sulfato de magnésio & 246,00 \\
Sulfato de potássio & 22,00 \\
Micronutrientes & $* *$ \\
\hline
\end{tabular}

* Adaptada de Castellane \& Araújo (1994) para a cultura do meloeiro

** Tabela 2

Tabela 2. Quantidade (mL 1000L-1) dos compostos utilizados como fontes de micronutrientes para composição da solução nutritiva $100 \%$ mineral

\begin{tabular}{lr}
\hline \multicolumn{1}{c}{ Produto } & $\mathrm{mL}$ \\
\hline Profol Ferro & 10,00 \\
Profol Manganês & 3,46 \\
Profol Cobre & 0,10 \\
Profol Molibdênio & 0,33 \\
Profol Zinco & 0,70 \\
Profol Boro & 1,55 \\
\hline
\end{tabular}

Para a solução de micronutrientes utilizou-se, como fonte, o produto comercial Profol, nas quantidades descritas na Tabela 2.

O Profol é um produto comercial à base de cloreto com alta solubilidade, produzido pela Produquímica Ind. e Com. Ltda.

A solução organo-mineral utilizada nos tratamentos 1 e 3 foi composta pelo biofertilizante complementado com adubos minerais, objetivando-se a formulação de uma solução nutritiva com as mesmas concentrações de nutrientes da solução nutritiva $100 \%$ mineral. Após a análise química do biofertilizante, exposta na Tabela 3, concluiu-se que este era rico em $\mathrm{P}, \mathrm{S}$ e micronutrientes sendo, portanto, utilizado como fonte desses elementos. Com isto, a solução organo-mineral foi composta por: $0,1 \mathrm{~L}$ de biofertilizante, com complementação mineral de 168; 222; 153 e 24,6 mg L ${ }^{-1}$ de $\mathrm{N}$; K; Ca e Mg, respectivamente. Os componentes utilizados como fontes de nutrientes na composição da solução nutritiva organo-mineral, podem ser visualizados na Tabela 4.

Em seguida, realizaram-se análises físico-químicas das soluções nutritivas, através das quais foram obtidas as concentrações de nutrientes, $\mathrm{CE}$ (condutividade elétrica) e $\mathrm{pH}$ nas amostras; já para a produção do substrato utilizado nos tratamentos 3 e 4, coletou-se a parte sólida do efluente já seco (em forma de "torrões") e procedeu-se à moagem; depois,

Tabela 3. Teores de nutrientes encontrados no biofertilizante em $\mathrm{mg} \mathrm{L}^{-1}$

\begin{tabular}{cccccccccccc}
\hline $\mathrm{N}$ & $\mathrm{P}$ & $\mathrm{K}$ & $\mathrm{Ca}$ & $\mathrm{Mg}$ & $\mathrm{S}$ & $\mathrm{Fe}$ & $\mathrm{Mn}$ & $\mathrm{B}$ & $\mathrm{Zn}$ & $\mathrm{Cu}$ \\
\hline 120,00 & 340,00 & 88,00 & 6,55 & 4,15 & 450,00 & 26,42 & 4,13 & 5,20 & 1,68 & ALD* \\
\hline * ALD - Abaixo do limite de deteç̧ão & & & & & & & & & &
\end{tabular}


Tabela 4. Quantidade dos constituintes usados no preparo da solução nutritiva organo-mineral

Componente Quantidade por Litro de Solução Nutritiva
Biofertilizante

Nitrato de cálcio

Cloreto de potássio

Nitrato de potássio

Profol magnésio
$100,00 \mathrm{~mL}$

$805,30 \mathrm{mg}$

$202,46 \mathrm{mg}$

$324,82 \mathrm{mg}$

$0,219 \mathrm{~mL}$ misturou-se o material moído com areia grossa lavada, em proporções de 1:1. Na Tabela 5A pode-se observar as concentrações de nutrientes encontrados no substrato.

As concentrações dos nutrientes encontrados nas soluções nutritivas $100 \%$ mineral (utilizada nos tratamentos 2 e 4) e organo-mineral (tratamentos 1 e 3) podem ser observadas, também, na Tabela 5B e C, respectivamente.

Os valores de $\mathrm{pH}$ e condutividade elétrica (CE) encontrados na análise físico-química da solução nutritiva $100 \%$, foram de 6,3 e 2,85 mS cm$~^{-1}$, respectivamente; na solução organo-mineral esses valores foram de 7,4 e $3,90 \mathrm{mS} \mathrm{cm}^{-1}$, respectivamente. Comparando-se os dados, observa-se que as duas soluções nutritivas obtidas não apresentaram valores idênticos quanto aos teores de nutrientes, sendo que a solução nutritiva organomineral apresentou maiores teores de $\mathrm{N}, \mathrm{K}, \mathrm{Ca}$ e $\mathrm{Mg}$ e menores teores de $\mathrm{P}$ e $\mathrm{S}$, quando comparada com a solução nutritiva $100 \%$ mineral. A maior quantidade de N, K, Ca e Mg na solução nutritiva organo-mineral, se explica pela complementação mineral adotada para esses nutrientes, enquanto os menores teores de $\mathrm{P}$ e $\mathrm{S}$ ocorreram devido à ausência da complementação mineral, tendo como única fonte o biofertilizante. Para os micronutrientes (com exceção feita ao $\mathrm{Fe}$ ) praticamente não houve diferenças entre as concentrações das duas soluções, apesar de não ter havido complementação mineral.

Quanto ao manejo da irrigação, no sistema fechado tipo NFT adotou-se a circulação intermitente da solução nutritiva, com 15 min circulando e 30 min desligado durante o dia e, à noite, duas irrigações, às 20:30 h e a 0:30 h. As vazões utilizadas nos canais de cultivo foram de aproximadamente $3 \mathrm{~L} \mathrm{~min}^{-1}$, conforme recomendação de Alpi \& Tognoni (1991) apud Castellane \& Araújo (1994). No sistema aberto (com substrato) irrigou-se uma vez por dia, até que a solução nutritiva começasse a escoar pelos orifícios inferiores dos canais de cultivo. Ressalta-se que em nenhum momento as plantas apresentaram sintomas visuais de deficiência hídrica nem, tampouco, falta de oxigenação.

O delineamento experimental utilizado foi em blocos casualisados, com 6 repetições e 4 tratamentos. Os blocos foram distribuídos dentro do ambiente protegido e os tratamentos, por sua vez, o foram aleatoriamente, dentro de cada bloco. Cada canal de cultivo, com $6 \mathrm{~m}$ de comprimento e 12 plantas, foi considerado uma parcela. O esquema de análise de variância adotado foi o fatorial 2 × 2 (2 sistemas de cultivo hidropônico e 2 tipos de solução nutritiva) com 6 repetições.

Os tratos culturais necessários para a condução da cultura foram realizados segundo as recomendações de Goto \& Tivelli (1998) buscando-se, sempre, um ótimo desenvolvimento da planta. Para condução das plantas, utilizou-se o sistema de tutoramento, no qual estas foram conduzidas verticalmente com auxílio de fitilho e em haste única, deixando-se 2 frutos por planta, conforme metodologia descrita por Goto \& Tivelli (1998). Ressalta-se que não foi necessário a realização da polinização manual, devido ao excesso de abelhas polinizadoras no local. A colheita foi realizada diariamente, quando os frutos apresentavam sinais de maturação.

Com o intuito de avaliar o efeito dos tratamentos no crescimento vegetativo das plantas realizaram-se, aos 50, 56, 63,70 e 77 dias após a semeadura (DAS) avaliações quanto à altura das plantas, para o que se mediu a altura de todas as plantas de cada parcela (12 plantas por parcela) com auxílio de uma régua graduada, com 2,5 m de comprimento. Considerouse a altura das plantas a distância entre o coleto da planta e o ápice da haste principal.

Após a obtenção da produção total em cada tratamento, calculou-se a produtividade média em $\mathrm{kg} \mathrm{m}^{-2}$, considerando-se todos os frutos comercializáveis; já para se conseguir o peso médio dos frutos em $\mathrm{g}$, pesaram-se todos os frutos comercializáveis de cada tratamento obtendo-se, em seguida, as médias.

Foram medidos os diâmetros transversal (região equatorial) e longitudinal de todos os frutos comercializáveis de cada tratamento, com auxílio de paquímetro digital Digimatic da marca Mitutoyo, modelo CD 6", Série 500, com precisão de 0,1 mm, sendo estas avaliações expressas em mm. Depois de obtidos os diâmetros de todos os frutos comercializáveis de cada parcela, obteve-se a relação entre eles. Deste modo, avaliou-se o formato médio dos frutos, ou seja, quanto mais próxima esta relação de 1 , mais redondo era o formato do fruto.

Os rendimentos relativos de casca, semente e polpa foram obtidos com base na relação entre o peso de cada uma dessas partes e o peso total do fruto, após a separação de cada uma das partes. Estes parâmetros foram expressos em $\mathrm{g} \mathrm{kg}^{-1}$.

Para as avaliações tecnológicas dos frutos (teor de sólidos solúveis totais, acidez titulável e $\mathrm{pH}$ da polpa) foram utilizados

Tabela 5. Concentrações de nutrientes encontrados no substrato(A), nas soluções nutritivas 100\% mineral(B) e organo-minerais $(\mathrm{C})$

\begin{tabular}{|c|c|c|c|c|c|c|c|c|c|c|}
\hline $\mathrm{N}$ & $\mathrm{P}$ & $\mathrm{K}$ & $\mathrm{Ca}$ & $\mathrm{Mg}$ & $\mathrm{S}$ & $\mathrm{Fe}$ & $\mathrm{Mn}$ & $\mathrm{B}$ & $\mathrm{Zn}$ & $\mathrm{Cu}$ \\
\hline \multicolumn{11}{|c|}{ A. Substrato $\left(\mathrm{g} \mathrm{kg}^{-1}\right)$} \\
\hline 6,650 & 6,300 & 1,020 & 0,230 & 0,150 & 6,200 & 3,800 & 0,027 & 0,003 & 0,013 & 0,003 \\
\hline \multicolumn{11}{|c|}{ B. Solução nutritiva $100 \%$ mineral $\left(\mathrm{mg} \mathrm{L}^{-1}\right)$} \\
\hline 170 & 33 & 260 & 134 & 15 & 42 & 1,9 & 0,5 & 0,4 & 0,4 & \\
\hline \multicolumn{11}{|c|}{ C. Solução nutritiva organo-mineral (mg L $\left.{ }^{-1}\right)$} \\
\hline $240^{3}$ & 31 & 290 & 149 & 21 & 36 & 1,8 & 0,4 & 0,5 & 0,3 & \\
\hline
\end{tabular}


10 frutos comercializáveis por planta, escolhidos ao acaso; por sua vez, o teor de sólidos solúveis totais (SST) foi determinado por refratometria, com um refratômetro portátil ATC da marca Átago, para o que foram colocadas algumas gotas de suco da parte mediana do mesocarpo do fruto entre os prismas do refratômetro, no qual, em seguida, se realizou a leitura. Este parâmetro teve seus resultados expressos em ${ }^{\circ}$ Brix.

Para determinação da acidez titulável (AT) expressa em g de ácido cítrico por $100 \mathrm{~mL}$ de suco, utilizou-se a técnica de titulação com hidróxido de sódio $(\mathrm{NaOH})$ a $0,1 \mathrm{~N}$, de acordo com a metodologia recomendada pelo Instituto Adolfo Lutz (1985); para isto, utilizou-se de amostra de $20 \mathrm{~mL}$ de suco extraído da polpa do fruto avaliado, além de 2 gotas de fenolftaleína a $0,1 \%$ como indicador. Enfim, o $\mathrm{pH}$ da polpa dos frutos foi determinado segundo metodologia recomendada pelo Instituto Adolfo Lutz (1985). Para tanto, depois de extraído o suco do fruto avaliado realizou-se a leitura, com auxílio de um peagâmetro portátil da marca Oakton.

\section{RESULTADOS E DISCUSSÃO}

Na Tabela 6 observa-se a altura das plantas do meloeiro aos 50, 56, 63, 70 e 77 DAS quando submetidas aos dois sistemas hidropônicos e às duas soluções nutritivas estudadas na presente pesquisa.

Pela Tabela 6 verifica-se que, em todas as épocas de amostragem, a média das alturas das plantas cultivadas em sistema fechado tipo NFT, superou a das cultivadas em sistema aberto com substrato devido, provavelmente, ao maior tempo de contato entre as raízes e a solução nutritiva no sistema fechado tipo NFT. Observou-se, também, que o sistema radicular das plantas cultivadas em NFT era visualmente maior podendo, com isto, ter ocorrido maior absorção de água e nutrientes, concordando com Jeannequin \& Fabre (1993) apud Rosa (1997). Por outro lado e de acordo com Cadahia Lopez (1998) quando uma solução nutritiva é aplicada a um substrato, esta pode reagir com seus componentes, sofrendo ações negativas, como efeitos osmóticos e antagonismos, prejudicando a absorção de nutrientes e, conseqüentemente, proporcionando menor desenvolvimento das plantas.

Na Tabela 6 observa-se, ainda, que não houve diferença significativa entre os valores médios da altura das plantas cultivadas com as duas soluções nutritivas aos 50, 56 e 63 DAS. Em contrapartida, aos 70 e 77 DAS ocorreu interação significativa entre os sistemas hidropônicos e as soluções nutritivas estudadas em nível de $1 \%$ de probabilidade, com diferenças significativas entre as médias dos tratamentos, sendo que as médias dos tratamentos 2 e 4 com a solução nutritiva $100 \%$ mineral superaram as médias dos tratamentos 1 e 3 com solução nutritiva organo-mineral.

O desdobramento das médias das alturas das plantas em função da interação significativa observada entre soluções nutritivas e sistemas hidropônicos aos 70 e 77 DAS encontrase na Tabela 7 .

A Tabela 7 revela que o menor crescimento das plantas com utilização de solução nutritiva organo-mineral só ocorreu dentro dos tratamentos com sistema fechado tipo NFT, não se constatando nos tratamentos em sistema aberto com substrato. Nesta tabela se observa, também, que o tratamento em sistema fechado tipo NFT com solução nutritiva $100 \%$ mineral foi o que apresentou a maior altura média das plantas, aos 70 e 77 DAS.

Aos 63 DAS notou-se que as plantas do tratamento $1 \mathrm{em}$ relação ao tratamento 2, começaram a apresentar menor desenvolvimento da parte aérea sem, no entanto, mostrar sintomas visuais de deficiência mineral. Depois de uma análise mais criteriosa, notou-se ainda menor desenvolvimento do sistema radicular dessas plantas em relação ao tratamento 2, apresentando um pequeno acúmulo de material sólido. Aos 70 DAS ficava mais evidente uma altura menor das plantas do tratamento 1 em relação ao tratamento 2, como pode ser observado na Tabela 7. Neste momento e apesar de menor

Tabela 6. Altura das plantas (cm) do meloeiro aos 50, 56, 63, 70 e 77 dias após a semeadura (DAS)

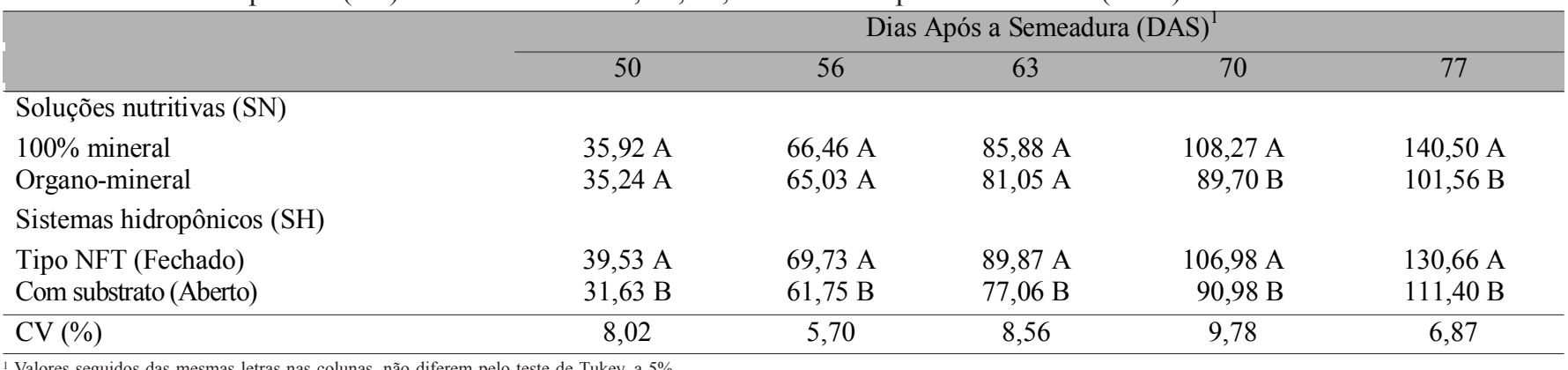

Valores seguidos das mesmas letras nas colunas, não diferem pelo teste de Tukey, a 5\%

Tabela 7. Desdobramento das médias ${ }^{1}$ das alturas das plantas $(\mathrm{cm})$ aos 70 e 77 dias após a semeadura (DAS)

\begin{tabular}{|c|c|c|c|c|}
\hline \multirow{3}{*}{ Sistemas Hidropônicos } & \multicolumn{2}{|c|}{70 DAS } & \multicolumn{2}{|c|}{77 DAS } \\
\hline & \multicolumn{2}{|c|}{ Soluções Nutritivas } & \multicolumn{2}{|c|}{ Soluções Nutritivas } \\
\hline & 100\% Mineral & Organo-Mineral & 100\% Mineral & Organo-Mineral \\
\hline Com Substrato (Aberto) & $92,48 \mathrm{Ba}$ & $89,48 \mathrm{Aa}$ & $113,20 \mathrm{Ba}$ & $109,60 \mathrm{Aa}$ \\
\hline $\mathrm{CV}(\%)$ & \multicolumn{2}{|c|}{9,78} & \multicolumn{2}{|c|}{6,87} \\
\hline
\end{tabular}


desenvolvimento, as plantas do tratamento 1 não apresentavam sinais visíveis de problemas nutricionais. Ao se observar o sistema radicular dessas plantas, constatou-se acúmulo de partículas sólidas provenientes do biofertilizante, formando uma camada sólida que impedia as raízes de se desenvolverem normalmente. Aos $77 \mathrm{DAS}$ as plantas cultivadas no tratamento 1 começaram a apresentar sintomas de murchamento e morte do sistema radicular, por falta de oxigenação sem, porém, apresentarem sintomas visíveis de deficiência nutricional. Aos 90 DAS todas as plantas do tratamento 1 foram eliminadas, pois estas já apresentavam sintomas de secamento total da parte aérea.

Com a eliminação do tratamento 1 , o delineamento experimental definido como fatorial $2 \times 2$ para o parâmetro altura de plantas, passou a ser de 3 tratamentos em blocos casualizados com 6 repetições para os demais parâmetros.

$\mathrm{Na}$ Tabela 8 observa-se a produtividade média (PE), o peso médio dos frutos (PM), o diâmetro médio longitudinal dos frutos (DL), o diâmetro médio transversal dos frutos (DT), a relação média entre diâmetro longitudinal e transversal dos frutos (RD) e os rendimentos médios relativos de casca, semente e polpa dos frutos do meloeiro submetido aos tratamentos 2 (sistema fechado tipo NFT com solução nutritiva $100 \%$ mineral), 3 (sistema aberto com substrato e solução nutritiva organo-mineral) e 4 (sistema aberto com substrato e solução nutritiva $100 \%$ mineral).

Verifica-se, analisando-se os dados apresentados na Tabela 8 , que a produtividade média alcançada no tratamento 2 foi de $3,391 \mathrm{~kg} \mathrm{~m}^{-2}\left(33,91 \mathrm{t} \mathrm{ha}^{-1}\right)$ superando significativamente as produtividades médias obtidas pelos tratamentos 3 e 4, de 3,044 $\mathrm{kg} \mathrm{m}^{-2}\left(30,44 \mathrm{tha}^{-1}\right)$ e $3,055 \mathrm{~kg} \mathrm{~m}^{-2}\left(30,55 \mathrm{t} \mathrm{ha}^{-1}\right)$ respectivamente, fato explicado pelo maior desenvolvimento vegetativo conseguido pelas plantas cultivadas em NFT (Tabela 6), resultando, provavelmente, uma área foliar maior e, também, maior taxa fotossintética; já na Tabela 8 observa-se que a utilização de solução nutritiva organo-mineral ou $100 \%$ mineral em sistema aberto com substrato (tratamentos 3 e 4) não proporcionou diferença significativa na produtividade média do meloeiro, razão pela qual se diz que, neste caso, a substituição parcial de adubos minerais por biofertilizante não causou perdas na produtividade; no entanto, analisado-se esta tabela, verifica-se que o peso médio dos frutos do tratamento 2 foi de $847,37 \mathrm{~g}$, superando significativamente o peso médio dos frutos obtidos nos tratamentos 3 e 4, que foram de 760,87 e $763,85 \mathrm{~g}$, respectivamente. Esta diferença pode ser explicada pelo maior desenvolvimento vegetativo alcançado pelas plantas cultivadas em NFT (Tabela 6) resultando, provavelmente, em maior área foliar e maior taxa fotossintética. Nos tratamentos em sistema aberto com substrato (3 e 4) não se observou diferença significativa no peso médio dos frutos para as duas soluções nutritivas estudadas.

As médias dos diâmetros longitudinais observadas na Tabela 8 , seguiram uma relação direta com o peso médio dos frutos, sendo que o tratamento 2 (sistema fechado tipo NFT com solução nutritiva $100 \%$ mineral) superou os tratamentos 3 e 4, nos quais se utilizou sistema aberto com substrato; já entre os tratamentos 3 e 4, os diâmetros médios longitudinais dos frutos não variaram significativamente para as duas soluções nutritivas estudadas; no entanto, nota-se, nesta tabela, que as médias dos diâmetros transversais não variaram significativamente entre os 3 tratamentos estudados.

A relação média entre os diâmetros longitudinal e transversal (RD) permite o conhecimento do formato médio dos frutos, sendo que valores maiores que 1 indicam frutos mais alongados, e valores menores que 1 , indicam frutos mais achatados. O conhecimento desse índice é importante para a definição da embalagem e do arranjo dos frutos; além disso, esta característica influencia na classificação e padronização dos melões, podendo determinar a melhor aceitação e valorização do produto para determinados tipos de mercado. Ainda na Tabela 8, pode-se observar que os diferentes tratamentos estudados apresentaram formatos diferenciados, e os frutos produzidos em sistema fechado tipo NFT com solução nutritiva $100 \%$ mineral (tratamento 2) apresentaram formato médio mais alongado $(\mathrm{RD}=1,05)$ enquanto os tratamentos em sistema aberto com substrato ( 3 e 4 ) produziram frutos com formato médio mais achatado, com $\mathrm{RD}=0,96$. Ressalta-se que esses valores estão próximos do valor 1 , recomendado por Grangeiro et al. (1999) para o híbrido Bônus $\mathrm{n}^{\mathrm{o}} 2$. Os rendimentos relativos médios de casca, semente e polpa dos frutos apresentados na Tabela 8 , não variaram significativamente entre os tratamentos estudados.

Observam-se, na Tabela 9, os dados referentes às avaliações tecnológicas (teor de sólidos solúveis totais, acidez titulável e $\mathrm{pH}$ da polpa) realizadas nos frutos do meloeiro submetido aos tratamentos 2, 3 e 4 .

Quanto à Tabela 9, o teor médio de sólidos solúveis totais (SST) encontrado nos melões produzidos em sistema fechado tipo NFT com solução $100 \%$ mineral, foi de $16,82{ }^{\circ}$ Brix, superando significativamente o valor médio do SST obtido daqueles produzidos nos tratamentos 3 e 4 (sistema aberto com substrato) de 14,97 e $15,18{ }^{\circ}$ Brix, respectivamente. Os valores médios das avaliações periódicas da altura das plantas (Tabela 6), revelam maior crescimento vegetativo das plantas

Tabela 8. Produtividade média (PE), peso médio dos frutos (PM), diâmetro médio longitudinal dos frutos (DL), diâmetro médio transversal dos frutos (DT), relação média entre diâmetro longitudinal e transversal dos frutos (RD) e rendimentos médios relativos de casca, semente e polpa dos frutos do meloeiro submetido aos tratamentos ${ }^{1}$

\begin{tabular}{ccccccccc}
\hline Tratamentos $^{2}$ & $\begin{array}{c}\mathrm{PE} \\
\left(\mathrm{kg} \mathrm{m}^{-2}\right)\end{array}$ & $\begin{array}{c}\mathrm{PM} \\
(\mathrm{g})\end{array}$ & $\begin{array}{c}\mathrm{DL} \\
(\mathrm{mm})\end{array}$ & $\begin{array}{c}\mathrm{DT} \\
(\mathrm{mm})\end{array}$ & $\mathrm{RD}$ & $\begin{array}{c}\text { Casca } \\
\left(\mathrm{g} \mathrm{kg}^{-1}\right)\end{array}$ & $\begin{array}{c}\text { Semente } \\
\left(\mathrm{g} \mathrm{kg}^{-1}\right)\end{array}$ & $\begin{array}{c}\text { Polpa } \\
\left(\mathrm{g} \mathrm{kg}^{-1}\right)\end{array}$ \\
\hline 2 & $3,391 \mathrm{~A}$ & $847,57 \mathrm{~A}$ & $119,75 \mathrm{~A}$ & $114,37 \mathrm{~A}$ & $1,05 \mathrm{~A}$ & $260,0 \mathrm{~A}$ & $95,7 \mathrm{~A}$ & $637,2 \mathrm{~A}$ \\
3 & $3,044 \mathrm{~B}$ & $760,87 \mathrm{~B}$ & $107,07 \mathrm{~B}$ & $112,02 \mathrm{~A}$ & $0,96 \mathrm{~B}$ & $264,8 \mathrm{~A}$ & $97,7 \mathrm{~A}$ & $618,5 \mathrm{~A}$ \\
4 & $3,055 \mathrm{~B}$ & $763,85 \mathrm{~B}$ & $107,97 \mathrm{~B}$ & $112,73 \mathrm{~A}$ & $0,96 \mathrm{~B}$ & $268,8 \mathrm{~A}$ & $95,7 \mathrm{~A}$ & $616,8 \mathrm{~A}$ \\
\hline $\mathrm{CV}$ & 6,25 & 6,26 & 3,36 & 2,51 & 3,47 & 4,63 & 9,42 & 2,85 \\
\hline
\end{tabular}

${ }^{1}$ Médias seguidas das mesmas letras nas colunas, não diferem pelo teste de Tukey a $5 \%$
${ }^{2} 2$ - Sistema fechado tipo NFT com solução nutritiva $100 \%$ mineral; 3 - Sistema aberto com substrato e solução nutritiva organo-mineral e 4 - Sistema aberto com substrato e solução nutritiva $100 \%$ mineral 
Tabela 9. Valores médios de teor de sólidos solúveis totais (SST), acidez titulável (AT) e pH do suco extraído dos frutos do meloeiro submetido aos tratamentos 2,3 e 4

\begin{tabular}{|c|c|c|c|}
\hline Tratamentos & $\begin{array}{c}\text { SST } \\
\left({ }^{\circ} \text { Brix }\right)\end{array}$ & $\begin{array}{l}\text { AT (g ácido cítrico } \\
100 \mathrm{~mL}^{-1} \mathrm{suco}^{-1} \text { ) }\end{array}$ & $\mathrm{pH}$ \\
\hline 2 (Sistema NFT com solução nutritiva $100 \%$ mineral) & $16,82 \mathrm{~A}^{1}$ & $0,148 \mathrm{~A}$ & $6,58 \mathrm{~A}$ \\
\hline 3 (Sistema aberto com substrato e solução nutritiva organo-mineral) & $14,97 \mathrm{~B}$ & $0,151 \mathrm{~A}$ & $6,68 \mathrm{~A}$ \\
\hline $\mathrm{CV}(\%)$ & 3,47 & 7,16 & 1,22 \\
\hline
\end{tabular}

${ }^{1}$ Valores seguidos das mesmas letras nas colunas, não diferem pelo teste de Tukey a $5 \%$

cultivadas em sistema fechado tipo NFT e, provavelmente, maior área foliar. Sem dúvida, esta condição explica a diferença no SST entre os tratamentos, concordando com Welles \& Buitelaar (1998) que afirmam que uma área foliar maior do meloeiro afeta positivamente o teor de sólidos solúveis totais do fruto. Entre os tratamentos 3 e 4, nos quais se cultivou o meloeiro em sistema aberto com substrato e soluções nutritivas organo-mineral e $100 \%$ mineral, respectivamente, não se observou diferença significativa no SST médio obtido dos frutos e, portanto, a substituição parcial de adubos minerais por biofertilizantes não proporcionou queda no SST dos melões.

Para a acidez titulável e o $\mathrm{pH}$ do suco, não foram encontradas diferenças significativas entre os três tratamentos estudados no presente ensaio.

Ressalta-se que os valores médios do peso (Tabela 8), e do SST obtidos dos frutos (Tabela 9) dos três tratamentos estudados na presente pesquisa, alcançaram valores considerados ótimos, segundo Brasil (1994). Este autor relata que um melão rendilhado precisa, para alcançar o mercado europeu, ter no mínimo um teor de sólidos solúveis totais de $12^{\circ}$ Brix e pesar entre 500 e $1000 \mathrm{~g}$.

Apesar do tratamento 2 (sistema fechado tipo NFT com solução nutritiva $100 \%$ mineral) ter apresentado maiores produtividade média, peso médio de frutos e teor médio de sólidos solúveis totais nos frutos, os tratamentos 3 e 4 (hidroponia aberta com substrato) apresentaram valores considerados satisfatórios para essas avaliações; assim, na escolha do sistema hidropônico a ser utilizado para a cultura do meloeiro, deve-se considerar, também, as desvantagens do sistema hidropônico tipo NFT, segundo Hanger (1986), Ueda (1990) e Castellane \& Araújo (1994) como: maiores custos de instalação, maiores riscos de perda por falta de energia elétrica, necessidade de monitoramento diário e maiores riscos de disseminação de doenças. Portanto, a utilização do sistema hidropônico aberto com substrato e solução nutritiva organo-mineral, pode ser uma boa opção para o produtor, sobretudo em propriedades onde já existam ou se reúnam condições para se instalar um biodigestor.

\section{CONCLUSÕES}

1. As plantas de meloeiro cultivadas hidroponicamente em sistema fechado tipo NFT com solução nutritiva 100\% mineral, apresentaram maiores valores médios quanto ao desenvolvimento vegetativo.

2. No sistema hidropônico fechado tipo NFT com solução nutritiva organo-mineral as plantas tiveram seu desenvolvimento prejudicado, devido a morte do sistema radicular.
3. O cultivo hidropônico em sistema fechado tipo NFT com solução nutritiva $100 \%$ mineral proporcionou ao meloeiro maior produtividade.

4. Os frutos produzidos nas plantas cultivadas em sistema hidropônico fechado tipo NFT com solução nutritiva $100 \%$ mineral apresentaram maior peso, formato mais alongado e maior teor de sólidos solúveis totais que aqueles produzidos em sistema hidropônico aberto com substrato.

5. A substituição parcial de adubos minerais por biofertilizante mostrou-se possível para o cultivo do meloeiro em sistema hidropônico aberto com substrato.

\section{AGRADECIMENTOS}

Os autores agradecem à FAPESP (Fundação de Amparo à Pesquisa do Estado de São Paulo) pela concessão de bolsa a nível de Mestrado (processo no 99/03709-1) e pelos recursos de auxílio a pesquisa concedidos, tornando possível a realização deste trabalho científico.

\section{LITERATURA CITADA}

Arias, C.H.J. Apuntes del proyecto "Xochicalli": casa ecológica autosuficiente. Texcoco: Unisersidad Autónoma Chapingo, 1977. 25p. Mimeografado

Arias, C.H.J. Digestión anaeróbica de desechos orgánicos. Texcoco: Universidad Autónoma Chapingo, 1981. 45p. Mimeografado

Brasil, Ministério da Agricultura, do Abastecimento e da Reforma Agrária. Melão para exportação: procedimentos de colheita e pós colheita. 1. ed. Brasília: EMBRAPA-SPI, 1994, 37p. Série Publicações Técnicas FRUPEX, 6

Cadahia Lopez, C. Fertirrigacion. Aspectos basicos. In: Cadahia Lopez, C. Fertirrigacion: Cultivos hortículas y ornamentales. Madrid: Mundi-Prensa, 1998. cap. 2, p. 63-79.

Castellane, P.D.; Araújo, J.A.C. de. Cultivo sem solo: hidroponia. Jaboticabal: FUNEP, 1994. 43p.

Fossati, C. Como praticar el hidrocultivo. Madrid: EDAF, 1986. $174 \mathrm{p}$.

Fries, M.R.; Aita, C. Aplicação de esterco de bovino e efluente de biodigestor em um solo podzólico vermelho-amarelo: efeito sobre a produção de matéria seca e absorção de nitrogênio pela cultura do sorgo. Revista do Centro de Ciências Rurais, Santa Maria, v.20, n.1-2, p.137-145, 1990.

Furlani, P.R. Cultivo de alface pela técnica de hidroponia. Campinas: Instituto Agronômico de Campinas, 1995. 20p. Documentos IAC, 55 
Furlani, P.R. Hydroponic vegetable production in Brazil. Acta Horticulturae, Wageningen, v.2, n.481, p.777-778, 1999.

Furlani, P.R.; Silveira, L.C.P.; Bolonhezi, D.; Faquin, V. Estruturas para o cultivo hidropônico. Informe Agropecuário, Belo Horizonte, v.20, n.200-201, p.72-80, 1999.

Goto, R.; Tivelli, S.W. Produção de hortaliças em ambiente protegido: condições subtropicais. São Paulo: Fundação Editora da UNESP, 1998.319p.

Grangeiro, L.C.; Pedrosa, J.F.; Bezerra Neto, F.; Negreiros, M.Z. de. Qualidade de híbridos de melão amarelo em diferentes densidades de plantio. Horticultura Brasileira, Brasília, v.17, n.2, p.110-113, 1999.

Hanger, B.C. The nutrient solution and its preparation. In: Hanger, B.C. Hydroponics for schools and the grower. Melborne: Victorian Schools Nursery. 1986. p. 21-33.

Instituto Adolfo Lutz. Normas analíticas do Instituto Adolfo Lutz: métodos químicos e físicos para a análise de alimentos. 3 ed. São Paulo: Instituto Adolfo Lutz, 1985. v.1, p.392-395.

Jensen, M.H.; Collins, W.L. Hidroponic vegetable production. Horticultural Reviews, New York, v.7, p.483-557, 1985.

Jones Jr., J.B. Hidroponics: its history and use in plant nutrition studies. Journal of Plant Nutrition, New York, v.5, n.8, p.10031030, 1982.

Lejeune, J.P.; Balestrazzi, E. L'importanza dell'acgua nella coltura idroponica. Informatore Agrário, Verona, v.34, p.71-5, 1992.
Mastrocola, P.C.B. Efeitos de diferentes quantidades de efluente de biodigestor, no desenvolvimento inicial de cultivares de milho (Zea mays L.) em casa-de-vegetação. Jaboticabal: UNESP, 1983. 118p. Trabalho Graduação

Rosa, E.A.S. Salinização em ambiente protegido. In: Foro Internacional de Cultivo Protegido, 1997, Botucatu. Anais... Botucatu: UNESP, 1997, p.226-262.

Ueda, S. Hidroponia: guia prático. São Paulo: Agroestufa, 1990. $50 \mathrm{p}$.

Valeriano, M.M. Efeito da incorporação de efluente de biodigestor no solo sobre o desenvolvimento e produtividade do milho (Zea mays L.). Jaboticabal: UNESP, 1987. 125p. Trabalho Graduação

Vázquez, J.O.S.; Rodríguez, A.C.; Hernández, J.A. Utilizacion de un biofertilizante en el cultivo de cebolla (Allium cepa L.) en Chapingo, Mexico. Revista Chapingo: Série Horticultura, Chapingo, v.1, p.95-99, 1995.

Volpe, C.A.; Minchio, C.A.; Barbosa, J.C.; André, R.B. Análise da precipitação mensal em Jaboticabal (SP). Ciência Agronômica, Jaboticabal, v.4, n.2, p.3-5, 1989.

Welles, G.W.H.; Buitelaar, K. Factors affecting soluble solids content of muskmelon (Cucumis melo L.). Netherlands Journal of Agricultural Science, Wageningen, n.36, p.239246, 1988. 